\title{
LAS DISEMINACIONES SEMÁNTICAS DE LA GULA EN JUAN DE ESPINOSA MEDRANO
}

\author{
Eduardo Hopkins Rodríguez \\ Pontificia Universidad Católica del Perú
}

Dividiendo los placeres en placeres del cuerpo y del alma, Aristóteles concentra la templanza y el desenfreno en los placeres corporales, mas no en todos ellos. La templanza y el desenfreno se dan, dice, "en los placeres en que participan también los demás animales, placeres que, debido a ello, ostentan su naturaleza servil y bestial, y que son los placeres del tacto y del gusto". (Aristóteles 1961: 82) Aristóteles subordina el gusto al tacto, y habla del placer corporal como "el goce que tiene su cumplimiento total en el tacto, sea en las comidas y bebidas, o en los llamados placeres del, amor. Por lo cual cierto glotón deseaba tener el gaznate más largo que una grulla, dando a entender con ello que su placer estaba en el contacto". (Aristóteles 1961: 82) Prosiguiendo con la índole animal de este sentido, declara que "el sentido en que reside el desenfreno es el más universal de los sentidos, y con razón parece ser el más vituperado, como que lo tenemos no en cuanto somos hombres, sino en cuanto somos animales. Bestial es gozarse en los placeres de este género y amarlos sobre todas las cosas". (Aristóteles 1961: 82) Siendo el deseo de comer algo natural, Aristóteles plantea que el exceso corresponde a la cantidad, al objeto, a la manera y al goce. 
(Aristóteles 1961: 83) Su evaluación conclusiva determina que es "manifiesto que el desenfreno es el exceso en los placeres, y que es vituperable". (Aristóteles 1961: 83)

Desde el punto de vista cristiano, la gula es un vicio y, de acuerdo con Santo Tomás de Aquino, se cataloga como "inmoderado placer en la comida y bebida" (Tomás de Aquino 1955: 2-2 q.148 a.6) y se la opone a la abstinencia y a la templanza. Reajustando criterios aristotélicos, como los ya aludidos, San Isidoro deslinda que en lo que se excede el goloso es en "la sustancia, en la cantidad, en el modo y en el tiempo". (Cit. por Tomás de Aquino 1955: 2-2 q.148 a.4) En relación con el pecado, Tomás de Aquino advierte que la gula "mata las virtudes por los vicios que de ella proceden". (Tomás de Aquino 1955: 2-2 q.148 a.2)

El concepto de gula en un tomista como Juan de Espinosa Medrano (Cuzco, siglo XVII) puede ser descrito como un campo semántico de gran riqueza simbólica que se constituye, a su vez, como una fuente de irradiación de significados metafóricos, alegóricos, analógicos, tipológicos, etc. Aquí importan las sustancias comestibles, las fases del proceso fisiológico de la digestión y sus alteraciones -incluyendo náuseas, purgaciones y las deyecciones como esputos, excrementos, y vómitos- así como las maneras y actitudes de mesa y las ocasiones u oportunidades de los actos de comer y beber. Cabe incluir entre los elementos de su amplio espectro semántico el ansia o la avidez de comer y el hambre. Asimismo, son pertinentes los valores opuestos a la gula como la abstinencia, el ayuno y la templanza. Igualmente, el sentido usual del término que incumbe a la problemática axiológica de los vicios y virtudes es materia tratada por el autor en varias ocasiones. La gula, como vitia carnalia, convoca una gama de enlaces con animales reconocidos por su voracidad, como el cerdo, entre otros, que serán variables de las construcciones de significados de Espinosa. Más interesante, aunque también es un sector de una temática frecuente en la tradición eclesiástica, es la connotación espiritual que se 
atribuye al acto de comer o de beber. En este último sentido, las conexiones con el misterio de la eucaristía son las más destacadas. Precisamente, el sacramento de la eucaristía corresponde, en tanto oposición, al vicio de la gula. (Sebastián 1988: 303) Complementando los factores de lo espiritual, las deficiencias que genera la gula en la faceta intelectual y en la capacidad cognoscitiva y especulativa, que han sido ampliamente estudiadas por los teólogos, sirven a Espinosa de sustento referencial. Adicionalmente, alrededor de la gula y sus correlatos y componentes, sean estos conjuntivos, disyuntivos o antagónicos con ella, Espinosa Medrano puede elaborar series analógicas con fines diversos en concordancia con sus específicas estrategias discursivas.

Para comprender el proceso de asignación de significados seguido por Espinosa Medrano debemos tomar en consideración que cuando la erudición cristiana transformó muchos aspectos del legado clásico "el plano de las ideas y el plano de la elocución, que fueron motivo en Grecia de permanente polémica en lo que concierne a su vinculación jerárquica y a su pertinencia en el discurso, fueron reducidos a la categoría de formas. En cuanto tales, los personajes, las historias, los casos, los temas, los mitos, terminan siendo portadores de valores poético-decorativos, alusivos, analógicos, metafóricos, ejemplares, tipológicos o prefigurativos. Valores que pueden resumirse en la alegorización, técnica fundamental en la producción y en la decodificación de significados, por lo menos, hasta el siglo XVIII. Pese a fuiertes corrientes de oposición, desde la Edad Media, el uso de la alegoría es normal en los sermones, hecho que permitió la familiarización del público con estos procedimientos y materiales, especialmente acogidos por las artes plásticas, la emblemática, el ceremonial religioso y el cortesano, el teatro y la literatura que, desde sus respectivas prácticas, reforzaron su difusión. La propia historia sagrada es también una importante fuente de signos que ya han sido resemantizados por comentaristas autorizados [...] y que, con el debido cuidado, pueden también ingresar al circuito de simbolizaciones del orador, según sus específicas intenciones”. (Hopkins 2002: 997-998) 
La metodología aplicada por Espinosa "parte del principio de que los signos constituyen entidades semánticamente inestables o vacías, abiertas para significar, o aptas para ser desprovistas de significado y ser motivo de sustituciones semánticas. Desde esta perspectiva, los signos son unidades disponibles para que el orador les asigne la significación apropiada al caso que deben servir o ilustrar. El carácter vacío de la significación en los signos, permite que el autor atribuya los significados en forma arbitraria, es decir, no sujeta a un acuerdo previo con el consenso de la sociedad. Esta es la razón por la que debe el autor exponer el componente de significados asignados en cada oportunidad". (Hopkins 2002: 999)

Bajo estos parámetros, examinaremos, en primer lugar, las aplicaciones del concepto de gula en su teatro de orientación religiosa. Espinosa Medrano compuso varias obras dramáticas en lengua quechua, con el propósito de promover la participación de los diversos estratos de la población andina del Cuzco en la doctrina cristiana y en sus respectivos rituales y festividades. El hijo pródigo (Meneses, ed. 1983), escrita probablemente a mediados del siglo XVII, estrictamente no es un auto sacramental, sino una fusión de auto sacramental con comedia en tres jornadas, dando como resultado una comedia religiosa de tipo sacramental que, como tal, estaba dedicada a rendir homenaje al sacramento de la Eucaristía durante las fiestas del Corpus Christi. La Eucaristía es el símbolo mayor de la Fe, que, como dice Emile Mâle, es "la virtud por la cual creemos en lo que no vemos". (Mâle 1972: 113) Como es previsible, en varios pasajes de la pieza se alude al pan eucarístico, así por ejemplo: "el Pan que eternamente comeremos" (15), "recordando mi Pan / harás tu vuelta, hijo" (16, cfr.19), "únicamente el Pan de Dios es el alimento" (80) "mi divino cuerpo en el Pan / cuando tenía que morir te di" (85) "Cercano a su muerte Cristo Jesús / al mediodía del Jueves Santo / se alegró de hacerse comida / para que se lleven los atribulados" (87, vid. 89). Un esquema fundamental está confrontando dos tipos de comida, una corporal, correspondiente a la gula, y otra espiritual, referida a la eucaristía. La parábola del hijo pródigo (Evangelio de San Lucas, 
Cap. XV), tema utilizado en varias ocasiones por el teatro español del Siglo de Oro, especialmente en autos sacramentales (cfr. Lope de Vega en 1604 o José de Valdivielso en 1622) ha sido ambientada en el mundo andino por medio de personajes alegóricos que fusionan su caracterización indígena con la de figuras simbólicas pertenecientes al ámbito de la tradición cristiana. La historia transita a través de la temática del arrepentimiento y el perdón, para culminar en la recepción eucarística, que es la que en última instancia motiva la acción dramática. La función instructiva, ejemplarizante, de la representación es indicada por el personaje Palabra de Dios cuando se dirige a los espectadores advirtiéndoles:

"Oyentes, mírense en él, así también ustedes se equivocan". (69)

Y más adelante:

"Así son los que abandonan a Dios, crían sus pecados como a cerdos; únicamente el Pan de Dios es el alimento, la cáscara del pecado es su purgante". (80)

Al estar la obra escrita en quechua, el campo de su recepción se restringe a la población nativa y a personas de procedencia hispana conocedoras de la lengua, como sacerdotes y seminaristas. Probablemente no se dirigía a toda's las jerarquías sociales del grupo andino, ya que hay críticas fuertes "a la clase señorial indígena. $\mathrm{Al}$ respecto, en la jornada $2^{\mathrm{a}}$, un cuidador de cerdos se queja de su patrón en estos términos:

"El amo inca es como el Demonio miserable, bravo, resondrador, castigador, y de hambre me mata". (70)

Efectivamente, el patrón aparece como uno de los demonios de la trama. Más adelante el cuidador de cerdos denuncia el mal trato que recibe de parte de este amo inca-demonio: 


\section{“(...) eres miserable,}

y eres rabioso, por más considerado

metes tus pies al recinto del hambre

y como al perro y la llama

a la gente haces padecer;

tampoco haces comer;

dices ya te daré, y luego

lo que das es medida de viento

que no sacia". (71)

Estas y otras frases que insisten en el tema del hambre denuncian las relaciones sociales conflictivas entre indígenas ricos y pobres, denuncia cuya presencia tiene por objetivo desprestigiar al sector señorial de este conjunto de la población. La estrategia de la identificación del grupo señorial con el demonio busca romper los lazos de poder incaicos, tratando de atraer simúltáneamente a los pobladores humildes hacia el cristianismo y el dominio hispano. Naturalmente, es posible que, al margen de las intenciones autoriales, se produjera espontáneamente en el receptor una traslación semántica que asociara tales críticas también a los patrones español y criollo. Otro aspecto que permite identificar al destinatario indígena del espectáculo consiste en el personaje Cuerpo, estructurado en parte como el gracioso de la comedia española y en parte como una figura burlesca andina. Es una especie de fuerza desorganizadora dominada por la pereza, la sensualidad y la gula, como un típico dios desordenador: Este personaje es rico en remisiones a la cotidianidad doméstica andina, así como en materia folklórica y en humor cómico grotesco. En lo que toca a la gula, tenemos las manifestaciones de la ansiedad voraz de Cuerpo:

"Choclo blando de Potosí, papa como hongo de Laicacota, hongos de Condorama, sois la alegría de mi corazón; contigo se vive feliz; sin ti parece que de hambre 
hasta mis intestinos se debilitan;

cuando tú estás en mi poder

hasta mi cuello engorda”. (18)

En otro momento, Cuerpo expresa sus gustos:
"mas bien digo, que venga la rica comida:
el guiso, jugos, la chicha y muchas ovas.
el olluquito con charqui, conchas y gelatina,
maíz sancochado y ensalada, estofado, maíz dulce y habas, carne no nacida y legumbres, choclos, frejoles cocidos, chicha dulce, hongos, humitas y porotos, paltas, ensalada de chichi, papas y frutas secas, chicha de maní, amarilla y blanca." (26)

En general, el lenguaje de la obra tiende a las alusiones crudas en lo concerniente a la realidad del pecado, resaltando el ángulo de descomposición y degradación material que este produce. Aquí la gula aparece como factor de degradación, como el vicio que "aproxima a los hombres con los animales". (Sebastián 1995:124) Es lo que se aprecia en la acción, cuando el pecador persigue los restos de alimento que dejan los cerdos. Por el tema y por la edad del personaje protagónico, cabe considerar que un sector de los espectadores a los que se destinaba esta pieza estaba conformado por jóvenes, a qụienes se buscaba orientar, según la usanza teatral de los denominados espejos de juventud.

Una segunda comedia religiosa de tipo sacramental en tres jornadas escrita en quechua de Espinosa es Rapto de Proserpina y sueño de Endimión (Meneses, ed. 1983, reproducida en Silva-Santisteban, ed. 2000), versión alegórica de temas mitológicos de Ovidio (Metamorfosis) y de El rapto de Proserpina de Claudiano, de acuerdo con la tradición de la interpretación alegórica medieval de Ovide moralisé (1291/ 1328) y Ovidius moralizatus (1342/1343) recopilados en 1484. 
(Frenzel 1976: 385). En la comedia de Espinosa, Plutón, identificado como el rebelde y torturado Luzbel, gobierna en la tierra y en el infierno, con poder sobre la luz y la oscuridad. Plutón, el demonio, que ha robado a Proserpina o el alma, posee los atributos simbólicos del poder incaico y rige en la tierra como una divinidad andina. El tema del pan eucarístico es introducido por Plutón cuando describe a Ceres, madre de Proserpina, como la Iglesia que prepara el pan para la comunión:

“(...) Ceres es su madre, esta mujer elabora el pan.

Ella encontró el trigo

para que se alimenten las gentes,

ella misma también lo anunció" (105)

Ceres se presenta a sí misma de la siguiente manera:

"Yo soy Ceres la amada, soy la madre de la que a menudo sufre.

Hice Pan del trigo,

-el Sol que brilla en la Cruz-,

es de mi corona; yo soy la Iglesia.

El Alma es mi hija

Y esta Hostia es mi escudo;

¿estás viendo?, por eso, con esta Cruz te venceré.

En este Pan está el Dios Sacramentado, Y en esta Cruz brilla crucificado.

Así con este Sol voy

Enseñando a todo el mundo". (110)

La identificación de Cristo o Endimión con "el verdadero sol" (106, 143-145) o "el sol que brilla en la Cruz" (110), como opuesto a Plutón, o el falso sol o el sol vencido, es un motivo constante en la obra, hecho que evidentemente lleva a buscar asociaciones con el culto solar entre los indígenas del Cuzco y a reconocer la estrategia de sustitución del mismo por el 
culto cristiano. Franklin Pease explica que "al iniciarse la conquista comenzó simultáneamente la evangelización cristiana, y los hombres andinos tuvieron que aceptar el cristianismo como culto oficial que desplazó al solar del Cuzco, al mismo tiempo que aceptaban la ruptura de un orden sagrado, de su mundo". (Pease 1973: 70) Para tal situación se debe considerar que "Cristo es el Sol de Justicia del cristianismo", que es como "aparece en muchos textos". (Pease 1967: 6) Es pertinente mencionar que la idea del sol de justicia en el cristianismo tiene entre sus bases el anuncio que figura en Malaquías 4, 2: "Mas para vosotros, los que teméis mi nombre, se alzará un sol de justicia, que traerá en sus alas la salud, y saldréis y saltaréis como terneros que salen del establo". Era de esperar que Espinosa aplicara la idea directamente, como efectivamente lo hace en uno de sus sermones: "el Sol de Iusticia Christo" (Espinosa 1695: Fol. 10) Con relación al mencionado reemplazo del culto al sol, César Itier indica que en el Cuzco "una de las celebraciones más importantes del calendario ritual precristiano era la del solsticio de invierno, que coincidía, en la época colonial, con el Corpus Christi y la representación de los autos sacramentales." Y en referencia al Rapto de Proserpina, Itier especifica que "el auto aprovechaba la tradicional importancia simbólica de ese momento crucial del ciclo anual para celebrar el triunfo del Verdadero Sol, es decir, Cristo, sobre el sol material al que los ancestros de los peruanos rendían culto en esa ocasión y del que Plutón asume varias funciones (oscurecer el sol, congelar las aguas, deshelar los nevados, etc.)". (Itier 1999: 219-220) Antoinette Molinié recuerda que el Corpus Christi europeo tiene también su propia "dimensión solar”. (Molinié 1999: 251) Para completar el panorama sobre este tema, consideraremos la opinión de Juan Polo de Ondegardo, quien explica que -desde el punto de vista indígena, y en una dirección interpretativa de signo inverso a la cristiana- las aproximaciones entre Corpus Christi e Inti Raymi fueron tomadas como fiesta del Inti Raymi nativo celebrado en el mes de junio: "Hase de advertir que esta fiesta cae quasi almismo tiempo que los Christianos hazemos la 
solemnidad de Corpus Christi, y que en algunas cosas tienen alguna apariencia de semejanza (como es en las danzas, representaciones, o cantares) y que por esta causa a avido y ay oy dia entre los indios que parecen celebrar nuestra fiesta de Corpus Christi, mucha superstición de celebrar la suya antigua del Intiraymi”. (Polo de Ondegardo 1584 [1916]: 21-22; cfr. Zuidema 1999: 191-192 y Molinié 1999: 250)

Es necesario tomar en cuenta que en la mitología latina Proserpina (Perséfone para los griegos) se relaciona con la primavera, y Ceres, diosa romana de los cereales (Deméter, en Grecia) corresponde a la agricultura. A su vez, Endimión es el pastor durmiente que sueña y está vinculado con el sol poniente. En cuanto a Plutón, se lo asocia con el mundo subterráneo (Pérez-Rioja 1971; Frenzel 1976). La lucha entre Plutón y Ceres concluye en la leyenda mitológica en una alternancia semestral respecto a la posesión de Proserpina por parte de ambas divinidades. Estas significaciones que provienen de la cultura grecolatina señalan el tipo de correlaciones que Espinosa toma en cuenta para enlazar los temas clásicos, los cristianos y los indígenas, alrededor del motivo del ciclo de las estaciones de la fiesta agrícola que el dramaturgo hace derivar hacia el concepto de fiesta eucarística.

Como Espinosa usa con regularidad materia mitológica clásica en esta composición, es probable que tuviera en mente un público compuesto por varones y mujeres de habla quechua familiarizado con la mitología clásica. Información que puede haberles llegado por diversas vías, tanto en castellano como en quechua, durante las fiestas públicas, los espectáculos teatrales, los sermones y, tal vez, algún tipo de escolarización. Acerca de este último punto, queda en duda si dicha escolarización abarcaba también a las mujeres nativas, pues en lo que afecta a los hombres de diverso nivel social entre los indígenas sabemos que sí recibieron educación escolar formal.

En otro tipo de discurso, como el de los sermones eucarísticos, son frecuentes las referencias al convite 
sacramental en tanto comida superior o sobrenatural opuesta a la normal o natural (Sebastián 1988: 303) Tales remisiones a la eucaristía y a la comunión dependen para sus variantes del aparato alegórico y simbólico que el ingenio y la erudición de Espinosa permiten desarrollar. Generalmente, se procura encontrar el enlace con el misterio del sacramento de la eucaristía en sus componentes fundamentales de cuerpo y sangre en concordancia con la riqueza simbólica que el sacramento conlleva. Las vinculaciones con diverso tipo de alimento tienen que ver particularmente con constelaciones asociadas al cuerpo o pan, tales como maná, trigo, cordero, aves, peces, lentejas, huevos, higos, y las asociadas a la sangre como uvas, vino, leche y miel. Se trata de asociaciones que la tradición y la erudición han consagrado en torno al tema de la encarnación de Cristo. La novedad radica en la creación o en la revelación de insólitas correspondencias, mediante la detección de prefiguraciones, sentidos alegóricos, morales, anagógicos. Estas correspondencias, en algunos casos, son inéditas y, en otros, pertenecen a comentaristas y exegetas de la sabiduría sacra. Incumbe al campo del convite eucarístico todo lo relativo a los aspectos humanos de la comida, la bebida, orígenes o fuentes, ingredientes, costumbres, maneras de mesa, predilecciones, fobias, etc. Pero también lo que atañe a la comida en el ámbito de lo animal y vegetal. Interesa lo pertinente a repulsiones y aficiones. En lo que concierne a la gula, naturalmente lo atinente a vicios y virtudes ocupa lugar central.

En Espinosa Medrano, la gula, adicionalmente a su posición como vicio, tiene un aspecto positivo, constituido por la ansiedad de la incorporación al convite eucarístico. Es el único caso en el que no cabe poner limitaciones a la voracidad, siendo esta en realidad una voracidad espiritual ajena a la gula.

El oficio de Espinosa como hombre de iglesia y predicador lo pone en contacto con las fuentes clásicas y teológicas en torno al vicio de la gula. "De las Aves la Perdiz 
(dezis allà) que también tiene sus adagios la Gula. De los Pezes el mas regalado es la Murena: La Murena tan preciada en la Antigüedad, que la sustentavan en los Estanques con carne humana". (Espinosa 1695: Fol. 1) En la erudición cristiana la Murena ha sido simbólicamente vinculada con el cuerpo de Cristo y Espinosa expone la simbología pertinente: "Hermoso Pez que, enroscándose siempre, haze gala de que brillen en circulo sus escamas. Pero que gusto tan estragado de Pez tan noble! Tiene amistad con la Serpiente, añudase en amorosos lazos con la Vivora; y es, que la Vivora la llama à silvos desde la orilla, mas para haver de solicitarla, primero dexa el veneno en alguna parte segura, escupe antes toda su ponçoña, y haviendo salido de el agua à los silvos la Murena, se abraçan tiernamente en vinculos de natural cariño: Despidense halagüeñas. Buelve la Vivora a tomar su ponçoña, y la Murena à sulcar las ondas por el piélago. Así Opiano y todos los Naturales. Mas quien os dixera, que en brutas laminas de la Naturaleza dibuxo su soberano Autor symbolos excelentes de aquel Augustissimo Sacramento? La Murena Peze destinado à las delicias es el Cuerpo de Christo en el plato Eucaristico (dixo Bercorio) Murena est Corpus Christi in Sacramento. Bien: mas quien sera la Vivora? Quien sino el hombre Pecador: Genimina viperarum, los llamava el Bautista, engendros vivoreznos. O fealdad serpentina la del pecado! Solicita la Vivora, ò Pecador à esta Murena; pero es allà por una Pasqua. Silvala, que silvo de Vivora es el susurro de la confession secreta: Ad istam igitur Murenam attrahend am in Paschate Vipera, idest Peccator sibilat per orationem. Bomita todo el veneno de sus culpas por la penitencia: Venenum, idest peccatum emquit per confessionem. Con que es admitida à los abraços de esta Murena, entrañandose con el Cuerpo de Christo en union intima de coraçones, y ayuntamiento estrecho de espiritus por la Sacramental Comunion. Et sicad copulam eius admittitur per Sacramentalem comunionem. Passa aquel fervor con la Pasqua, cessan las ternuras con la ocasión, y la Vivora vuelve por su ponçoña, y recogiendo otra vez el bomitado veneno de las confessadas culpas, se desliza lubricamente à sus cavernas: Sed statim post Pascha ad evomitum venenum, 
idest ad peccata confessa, et dimissa iterum revertitur, lib.10.c. vlt. Reduct. O! Dexa yà los venenos, ingrata Sierpe, que si por tu cuenta llamaste à silvos una vez à esta Mystica Murena, oy te solicita por la suya, esperandote ocho dias publicamente expuesta à las riberas del occeano de sus piedades, llamandote esta, no yà sordo silvo, si no el eco solemne de tanto clarin de oro, o Predicador docto, como por esta Octava te vozea". (Espinosa 1695: Fol. 1)

En relación con la conocida metáfora del pan y el vino eucarísticos como lluvia de oro, Espinosa introduce el caso de Heliogábalo: "Allà en sus mesas Heliogavalo manjares de oro, y plata mandava servir à sus combidados; pero en metal indigesto, y rigido. Quedavase en ayunas el huesped con un Capon de Plata, con un Pavo de Oro; platos que no alimentavan, pero enriquezian". Por oposición, en cambio, en el banquete eucarístico explica Espinosa que "es el Oro vianda; pero caudal; bebida, pero tesoro; no solo se harta la hambre, pero queda rica la mendiguez; ventura de los hombres, que mas jubilo causo a Maria en la Encarnacion de el Hijo de Dios". (Espinosa 1695: Fol. 35-36)

El águila cebándose en el corazón de Prometeo, así como la forma en que el pelícano alimenta a sus polluelos, aunque constituyen conexiones tópicas en la exégesis cristiana, adquieren en Espinosa una significación específica dentro del espectro alusivo de la gula.

Asumiendo que la consagración del pan y el vino se realiza como remembranza agradecida del sacrificio de Cristo, Espinosa conduce la materia de la memoria ritual hacia un plano intelectual: "comase con ella [la eucaristía], a lo racional, comase con conocimiento, y reconocimiento, lo demàs es de brutos, que quien no tiene memoria, tampoco parece tiene entendimiento". (Espinosa 1695: Fol. 5) Esta idea se amplifica conceptistamente en la metáfora de la eucaristía como libro: "A las altísimas cumbres de el Empyreo avia remontado las alas el Aguila de Pathmos [Juan], absorto estaba el 
Evangelista a tanto golpe de Misterios, como se le revelava en Espiritu, quando le dixo un Angel: Toma Iuan, come esto. Reparo en lo que le dava, y vio, que le ofrecia un libro: Accipe librum, et devora illum. Libro? Pues un libro se ha de comer? No, si no que lo ha de tragar: Devora illum. Que ni aun quiere, que lo masque. Valgame Dios! El libro se come? Quien podra tragarse un tomo entero? Que libro es este? Que ha de ser (dicen Alberto magno, Santo Thomas, Bernardino y otros) sino aquel Divinissimo Sacramento, donde enquadernada la divinidad con lo corpóreo, vemos, que se escribió el Verbo, o la Palabra de el Padre en el carneo pergamino de nuestra mortalidad: Esse es el libro, que os da el Angel del Sacerdote, libro sellado de cifras, caracteres, y rasgos incógnitos, y revesados, volumen arrollado en las obscuridades de la Fe, en que el mas despabilado ingenio abate las alas de su perspicacia, escrito por de dentro, y fuera. Lo de adentro no se lee, ni lo leyò Agustino, ni Thomàs: que Thomàs, y Augustino [sic], de los de la cubierta decoraron algunos renglones, ni quien podrà hojear el libro, si no sin examen, sin registro creerle, y comerle, que por eso dixo el Angel: Devoro. Que lo tragasse. Porque el mazcar es examen de el gusto. Quien mazca brujulea el sabor, y da traslado al paladar. Aquí la Esperança abre la boca, cierra los ojos la Fè, y traga la Caridad: Devora illum. No entra aquí la mia; que esto parece comun. Mi reparo està, en que lo que se come es libro, y es, porque es Pan de vida; es el comer acto de vida, pero comun à brutos, y à hombres, $\mathrm{y}$ como este es manjar de vida intelectiva: Panem vitae, et intellectus, quiere, que el comer sea entender, y sea leer el gustar. Porque como el comer sin entendimiento es de bestias, y solo pueda leer quien tiene entendimiento quiere sea plato literario, ò libro comestible, solicitando, no à quien le trague como bestia, si no à quien le deletree como entendido". (Espinosa 1695: Fol. 5)

Como puede observarse, se trata de una voracidad intelectual y espiritual. Sobre el pårticular, recordemos que se considera que el don que se opone a la gula es el de la ciencia. (Sebastián 1988: 303) Tomás de Aquino manifiesta que entre 
los desórdenes del alma que ocasiona la gula se halla el de la razón, "cuya agudeza se obtusa debido al exceso de comida y bebida, se encuentra la ceguera mental, originada por la fumosidad de los alimentos que llegan a perturbar la inteligencia, mientras que la abstinencia fomenta la agudeza de percepción". Y concluye que "todo pecado produce cierta estupidez. Pero la estupidez acerca de las verdades especulativas tiene su origen en la gula ". (Tomás de Aquino 1955: 2-2 q.148 a.6)

En cuanto al asunto de lo intelectual asociado al comer, en un texto no religioso titulado "Panegírica declamación por la protección de las ciencias y estudios”, Espinosa ha recuperado la antigua figura de las abejas enlazadas con el conocimiento: "¿Quién no sabe con Varrón y Pierio que las abejas fueron viva imagen de los doctos, noble representación de los estudiosos?, que de las amenísimas selvas que tanto libro forma de sus hojas y de los caudalosos ríos de sabiduría que las inundan, pican vivezas, cogen flores, beben rocíos". (Espinosa 1982: 120) En este discurso el asunto de las abejas y el intelecto se expande a través de cadenas analógicas hasta conectar con Santo Tomás y sus seguidores, entre ellos el propio Espinosa Medrano.

Así pues, el tema de la avidez intelectual pertenece al complejo espacio semántico de la gula y Espinosa Medrano lo presenta con agudeza desde varias perspectivas.

Es una franja del archivo temático de la gula el episodio de la cena de Trimalción en el Satiricón de Petronio. Espinosa acude en varias ocasiones durante sus sermones a este lugar de la gastrosofía latina, tomando materiales para el diseño de sus alegorías. En su "Oración Panegírica a la renovación de el santísimo sacramento", del 6 de agosto de 1662, comienza así la Salutación: "Celebre Fue aquel Combite de Trimalcion, que solemnizò Petronio: en aquella mesa espantosa, ni las baxillas con opulencia, ni las viandas sin numero llegaron à embargar la admiración tanto, como un plato, que se sirvió 
mas al assombro, que a la golosina, no pareciò grande al empeño de la obstentacion [...]; pero llevòse los ojos por la novedad". (Espinosa 1695: Fol. 10) Se refiere al plato cuyos manjares estaban expuestos en concordancia con los signos del zodiaco y rodeando un panal de miel. La derivación de la imagen conduce a esclarecer que el signo del mes de agosto en que le corresponde pronunciar su discurso es el de Virgo, es decir, el de la virgen María, cuya imagen lleva una espiga (eucaristía). La secuencia de correlatos incluye la alusión a Cristo como el Sol de agosto, transfigurado por la Virgen en pan.

En la Salutación del "Sermón del miércoles de Ceniza" (1679), Espinosa utiliza también la escena de Trimalción en torno a la gula y asume, en antítesis, el tema de la salvación basada en el ayuno: "Profano como costoso era aquel banquete de Trimalcion, que describe Petronio, viandas exquisitas, y vinos admirables desafiavan à la gula, desenfrenavase el deleyte; y porque todo combidado se entregase brutamente à la tragazon; traxeron para estimularlos una muerte de plata a la mesa: Larvam argenteam attulit seruus. Un esqueleto forjado de este metal, ò figura de la muerte, que se plantò entre los Platos; levantò luego la voz Trimalcion: Sic erimus cuncti, postquam nos auferet Orcus, / Ergo vivamus dum licèt esse benè. En esto hemos de parar, si nos arrebata el infierno, y así comer, gozar, vivamos mientras vivimos. Que mala consecuencia, Ergo vivamus! La Iglesia argumenta oy mejor, procede à lo contrario; que para que ayunemos nos trae el simulacro de la Muerte, acuerdanos el sepulcro, pero para la Abstinencia. Ayunemos, dize, que avemos de parar en Ceniça [...]". (Espinosa 1695: Fol. 282)

La temática del ayuno pertenece al espacio de la gula como factor de contradicción beneficiosa. El ayuno no solamente es saludable, sino que fortalece el espíritu contra el pecado. Siguiendo a S. Ambrosio, Espinosa recuerda que "la saliva del hombre en ayunas mata la serpiente". Aplica el orador la referencia a S. Antonio el Magno: "Antonio, pues, como no solo estaba en ayunas, pero con la más espantosa 
abstinencia de noventa años de pan, y agua, de quatro à quatro dias probava solo un mendrugo con sal, viendo Dragon tamaño, apelo al vigor de tan raro ayuno, y como quien dize: si la saliva del ayuno mata Basiliscos, à hostilidad de Dragon tan grande, saliva de sobriedad tan portentosa, y disparándole la espumosa bala de sus labios, derroco subitamente al infernal espectro". (Espinosa 1695: Fol. 181-182)

He tratado de mostrar la presencia de las diseminaciones semánticas de la gula en Juan de Espinosa Medrano, señalando algunos de los modelos que pone en juego en su teatro evangelizador y en sus sermones eucarísticos. Debo indicar que si bien el concepto mayor en la obra religiosa de Espinosa es el de la comida y el comer -con sus múltiples correlaciones científicas, mitológicas, costumbristas y teológicas- es la gula, como caso particular del sector de los alimentos y la alimentación, un centro de irradiación simbólica fundamental para las especulaciones en lo tocante al misterio de la eucaristía, la virtud y el pecado.

\section{BIBLIOGRAFÍA}

AQUINO, Tomás de.

[1955] Suma Teológica. Madrid: Biblioteca de Autores Cristianos.

ARISTÓTELES

[1961]

Etica nicomaquea. Versión, prólogo y notas de A. Gómez Robledo. México: UNAM, 1961.

ESPINOSA MEDRANO, Juan.

1695

[1982]
La novena Maravilla. Valladolid.

"Panegírica declamación por la protección de las ciencias y estudios que incumbe al señor Maestre de Campo Don Juan de La Cerda y de la Coruña”. En: Espinosa Medrano, Juan de. Apologético. Caracas: Biblioteca Ayacucho, págs. 111-126. 

de Endimión". En: "Meneses, Teodoro, ed. Teatro Quechua Colonial. Antología. Lima: EDUBANCO. [2000] "Rapto de Proserpina y sueño de Endimión". En: Silva Santisteban, Ricardo. Antología General del Teatro Peruano. I. Teatro Quechua. Lima: BBV Banco Continental; Pontificia Universidad Católica del Perú, Fondo Editorial.

FRENZEL, Elisabeth

1976 Diccionario de argumentos de la literatura universal. Madrid: Gredos.

HOPKINS, Eduardo

2002

"Problemática del receptor en Juan de Espinosa Medrano" En: Homenaje Luis Jaime Cisneros. Lima: Pontificia Universidad Católica del Perú, Fondo Editorial, Tomo II, págs. 973-1007.

ITIER, César. 1999

"Los problemas de edición, datación, autoría y filiación de El robo de Proserpina y sueño de Endimión, auto sacramental colonial en Quechua". En: Arellano, Ignacio y Rodríguez Garrido, José Antonio, eds. Edición y anotación de textos coloniales hispanoamericanos. Madrid: Universidad de Navarra, 213-231.

MÂLE, Emile 1972

The Gothic Image. Religious Art in France of the Thirteenth Century.

New York: Harper and Row, Icon Editions.

MOLINIÉ, Antoinette 1999

"Dos celebraciones "salvajes" del cuerpo de Dios (Los Andes y La Mancha)" En: Molinié, Antoinette, ed. Celebrando el Cuerpo de Dios. Lima: Pontificia Universidad Católica del Perú, Fondo Editorial, 245-282. 
MOLINIÉ, Antoinette, ed.

1999

Celebrando el Cuerpo de Dios. Lima: Pontificia Universidad Católica del Perú, Fondo Editorial.

PEASE G. Y., Franklin

1967

En torno al culto solar incaico. Separata de Humanidades 1 Lima.

1973 El dios creador andino. Lima: Mosca Azul.

PÉREZ-RIOJA, José Antonio.

1971 Diccionario de símbolos y mitos. Madrid: Tecnos.

POLO DE ONDEGARDO, Juan

1584 [1916] Informaciones acerca de la religión y gobierno de los incas. Lima: Sanmarti. Colección de libros y documentos referentes a la historia del Perú. Tomo III.

SEBASTIÁN, Santiago

1988 Iconografía medieval. Donostia: Etor.

1995 Emblemática e historia del arte. Madrid: Cátedra.

ZUIDEMA, Tom 1999

"La fiesta del Inca". En: Molinié, Antoinette, ed. Celebrando el Cuerpo de Dios. Lima: Pontificia Universidad Católica del Perú, Fondo Editorial, 191-243. 